Original scientific paper

\title{
NUMERICAL SIMULATION OF COARSE PARTICLE TWO- PHASE FLOW IN TWO-STAGE VORTEX PUMP
}

\author{
Shi, H. X.; Meng, J. ${ }^{\#} \&$ Li, Y. \\ College of Mechanical Engineering, Hefei University of Technology, Hefei, 230009, China \\ E-Mail: jianm@mail.hfut.edu.cn (" Corresponding author)
}

\begin{abstract}
Vortex pumps are finding increasing use where abrasive fluids in petrochemical applications must be handled when pressure is readily available for transporting mixed materials in pumping applications. Related research on fine particle two-phase flow cannot meet the actual production requirements. Therefore, the characteristics of solid-liquid two-phase flow with high solid-phase content in pumps must be investigated. In this study, a two-stage vortex pump with a high demand for passing and steady ability is designed. The external characteristics of the pump, internal pressure field, velocity field, and solid distribution law are explored through high solid concentration and size changes. Results show that the shear stress transport turbulence model is found to be appropriate for the computational fluid dynamics analysis of the characteristics of the vortex pump well. The particle velocity and pressure at the monitoring point at the tongue of the volute are higher, thereby aggravating the wear. With the increase in particle volume concentration, the energy exchange between the media increases, and the hydraulic loss of the flow field increases.

(Received in August 2021, accepted in November 2021. This paper was with the authors 1 month for 1 revision.)
\end{abstract}

Key Words: Vortex Pump, Two-Phase Flow, Particle Diameter, Particle Concentration

\section{INTRODUCTION}

As one of the most crucial strategic resources in the world today, petroleum is the lifeblood of a country's modern economy, which is directly related to the country's economic development, political stability, and national security $[1,2]$. In recent years, the heavy quality, deterioration, and high vulcanization of global crude oil are the main trends of the change in crude oil quality worldwide [3, 4]. Therefore, oil refining enterprises tend to innovate residue deep processing equipment, increase the yield of light oil, improve the utilization rate of crude oil, and refine the quality of crude oil. With the incessant progress and improvement of technology, ebullated bed vacuum residue hydrocracking technology has become the preferred option for the processing of inferior crude oil in the future [5]. Decompression tower bottom supervaporization oil pumps (hereinafter referred to as pump) are heavy-duty high-temperature process pumps in large-scale oil refining units. The pump's type is vortex pump, which is the basic core equipment in oil refining units. Such pumps play a considerable role in the processing of inferior crude oil, that is, they are used to increase the pressure and ensure the normal operation of the system. When conveying liquid-solid mixed materials in the actual production process, solid concentration [6], particle size [7], shape [8], and density [9] have a certain influence on the stable operation of the pump. A spurt of progress has been witnessed in the petrochemical industry in recent years. Traditional studies on fine particle solid-liquid twophase flow cannot satisfy the design requirements of the coarse particle pumping system in the petrochemical field because the physical properties of the coarse particle and fine particle considerably differ in the material pumping system. The flow channel is blocked and worn by coarse particles easily, resulting in a significant reduction in the pump head's hydraulic efficiency, reliability, and service life. Serious blockage and the wear and tear of the flow channel threaten the safety of the system and the personnel.

Based on the above observations, scholars have conducted substantial research on the flow field characteristics of two-phase flow pumps [10-12]. However, most related studies have 
focused on the effects of low solid-phase content materials on the external characteristics and flow field of the pump. Research on the effect of materials with high solid-phase content on two-phase flow pumps is limited. For multistage vortex pumps with a special structure, the influence of high-particle-size and high-volume-concentration particles on the internal flow field characteristics is unknown. Therefore, an in-depth and accurate research on the external characteristics of multistage vortex pumps with high solid-phase content and the influence of the flow field must be conducted. Computational fluid dynamics (CFD) has developed rapidly and made remarkable achievements in fluid mechanical dynamics analysis. This process has the advantages of minimal investment, short period, complete information, and strong simulation ability, and can greatly reduce the cost of test equipment. In this study, a new type of multistage vortex pump is used to explore deeply the influence of high-particle-size and highvolume-concentration particles on the performance of the pump. The wear position of the pump is predicted through numerical calculation, and the wear degree of the wall is qualitatively analysed. This study is expected to provide some reference for solving the problems of wear and energy loss in practical engineering.

\section{STATE OF THE ART}

With the rapid development in the industry, vortex pumps have been widely used to transport solid-liquid two-phase mixtures. In the aspect of green energy saving, the low efficiency of two-phase mixed transport has gradually attracted the attention of researchers. Compared with single-phase flow, the complexity of solid-liquid two-phase flow increases considerably, and the interaction between fluid and machinery and the movement law of particles in the pump channel become more complex. Thus, scientific calculation methods must be established and reasonable design methods must be summarized. Scholars worldwide have established many flow models and conducted substantial flow research and analysis. A particle eroding model established by Ben-Ami et al. can accurately predict the wear law of the particle impingement angle and impact velocity on the wall surface after calculation and experiment $[13,14]$. Regarding the erosion of solid particles on the wall surface, the erosion rate equation was validated by Lin et al. [15], who took the size, shape, velocity, impact angle, and mass of particles as independent variables and evaluated the results. He found that when the particle size is between 75-600 $\mu \mathrm{m}$, the effect of particle sharpness on the degree of erosion avoidance is greater than that of particle size. Kamyar et al. [16-18] studied the flow characteristics of slurry in horizontal U-shaped bends. The effect of particle diameter on particle distribution and pressure drop in U-shaped bends was studied by using the dual Euler method. The results show that the pressure drop increases with the increase in flow velocity. The increase in particle diameter results in the increase in pressure drop at a low speed and vice versa. Kannojiya et al. [19-22] explored the erosion rate of particle size, concentration, and pipe roughness at different flow velocities for low carbon steel elbows. The results show that the growth trend of the erosion wear of the pipeline tends to stabilize with the increase in particle size. The wear speed of the pipeline first increases rapidly and then tends to increase slowly with the increase in roughness. Zhang et al. [23-25] investigated the effects of pipe diameter, particle size, particle composition, concentration, and mixing velocity on the flow characteristics in $900 \mathrm{~mm}$ horizontal pipes. With the increase in average particle size, the symmetry of the total particle concentration distribution of the mixed size slurry in the upper and lower parts of the pipe changes in varying degrees with the increase in particle size. Conducting related research on the pump combined with the test is technically crucial. The particle velocity in the internal flow field of the pump can be studied by using particle image velocimetry. Kadambi et al. [26] found that the pulsation energy is positively correlated with the rotational speed, and the influence on the pressure side of the blade and near the spacer tongue is supreme. The cause of wear on the 
tongue of the slurry pump is described in detail, but the mechanism of flow wear in the pump is not explained in detail. Yang et al. [27] measured the internal flow field of a self-designed vortex salting-out two-phase flow pump by using a phase Doppler particle analyser and obtained the 3D velocity distribution of each phase in the impeller. He concluded that the lowest particle concentration is near the inlet of the impeller and the back of the blade near the rear cover plate of the impeller. The circumferential velocity distribution of the liquid-solid phase in the impeller and the impeller cavity vary. The Euler multiphase flow model and RNG $k-\varepsilon$ two-equation turbulence model were adopted by Zhang et al. [28] to predict the small diameter and low concentration of the particle in CFD numerical calculation software. The results show that the solid particles are mainly concentrated in the vaneless cavity after entering the pump. With the increase in concentration, the distribution of particles in the leafless cavity mostly does not change, and the particles in the leafless cavity show a certain axisymmetric distribution around the pump shaft. A group equilibrium model called population balance model (PBM) based on the original Euler model was introduced by Qian et al. [29] to obtain more physical and realistic liquid-solid two-phase flow characteristics in the vortex pump. He examined the particle distribution of different particle diameters and volume concentrations under different flow conditions and different calculation models. Qian's experimental results show that the results of the loading PBM are consistent with the experimental data, but the cause for the change in flow field in the pump after loading PBM is not explained.

The existing numerical calculations of two-phase flow pumps mainly focus on the analysis of the single-stage pump and the internal flow field of the solid-liquid two-phase flow with a low concentration of fine particles. Only a few numerical studies are related to high mass holdup. The mechanism of solid-liquid two-phase flow with coarse particles must be investigated to develop the theory of solid-liquid two-phase flow. Given the lack of multistage vortex pumps in the market, research data on the high mass content of multistage vortex pumps are limited. In summary, research on liquid-solid two-phase flow in the field of vortex pumps still needs to be explored. Thus, this study uses a solid-liquid two-phase flow method based on multistage vortex pumps to study the performance law of the multistage vortex pump with high solid-phase content and provide some reference for the optimization of the wear performance of multistage vortex pumps.

The rest of this study is organized as follows: Section 3 describes the structure of the new vortex pump and the calculation method of two-phase flow and verifies grid independence in detail. Section 4 verifies the practicability of the turbulence model and then explores the effects of particle size and concentration on the external characteristics and internal flow field of the vortex pump. Section 5 summarizes this study and provides relevant conclusions.

\section{METHODOLOGY}

\subsection{Geometry}

A pump of 2.6 million t/a ebullated bed residue hydrogenation (including PSA) (80-50HDD$350 \times 2 \mathrm{~b}$ pump model) is taken as the research object. The pump adopts a two-stage back-toback vortex structure to reduce the axial force caused by impeller rotation. For consistency with the actual test, precrushing and crushing impellers are added in front of the first-stage impeller to refine the particles when establishing the pump device model, which are not discussed in this study. The pump studied in this work has the following measurements: rated flow $Q_{t}=19.7 \mathrm{~m}^{3} / \mathrm{h}$, rated head $H=362 \mathrm{~m}$, revolving speed $n=2980 \mathrm{r} / \mathrm{min}$, pressure at the outlet $p_{o}=3.29 \mathrm{MPa}$, inlet diameter $d_{i}=80 \mathrm{~mm}$, outlet diameter $d_{o}=50 \mathrm{~mm}$, number of the first-stage blades $Z=10$, firststage impeller diameter $D_{0}=400 \mathrm{~mm}$, and first-stage blade thickness $t=10 \mathrm{~mm}$. Fig. 1 shows the hydraulic structure of the pump. 


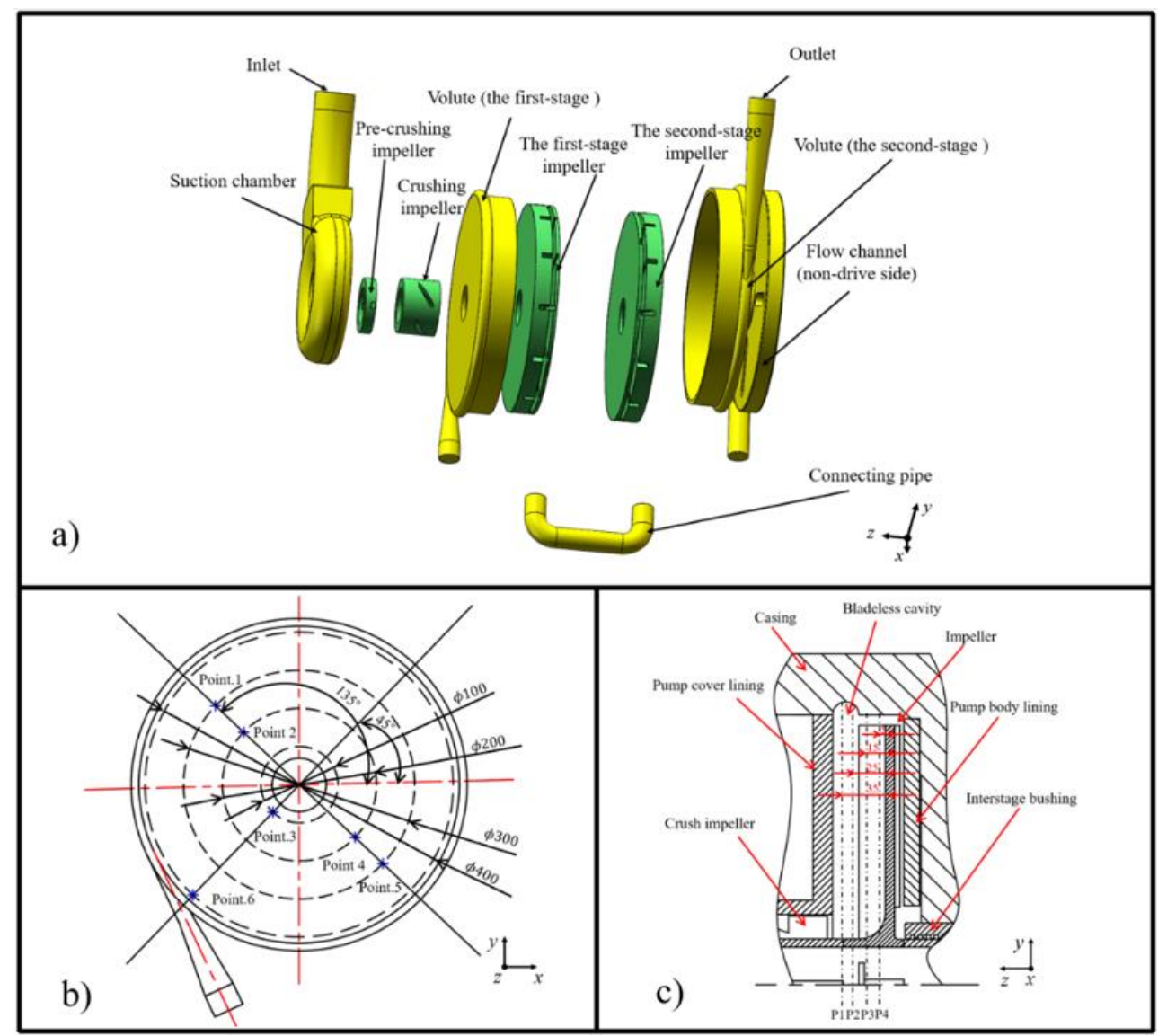

Figure 1: Hydraulic model of the pump: a) three-dimensional hydraulic structure, b) measuring point location on the first-stage impeller, c) internal structure of the pump at the first-stage impeller (all six points are set at the profile of $\mathrm{P} 1$ ).

\subsection{Mathematical model}

(1) Two-phase flow model

Considering the interaction between solid and liquid phases, the particle model based on the dual Euler method is selected in this study. The motion equations of the solid-liquid twophase flow in the Eulerian coordinate system are as follows [30].

Continuity equation:

$$
\left\{\begin{array}{c}
\alpha_{l}+\alpha_{s}=1 \\
\frac{\partial\left(\alpha_{l} \rho_{l}\right)}{\partial t}+\nabla \cdot\left(\alpha_{l} \rho_{l} \vec{v}_{l}\right)=0 \\
\frac{\partial\left(\alpha_{s} \rho_{s}\right)}{\partial t}+\nabla \cdot\left(\alpha_{s} \rho_{s} \vec{v}_{s}\right)=0
\end{array}\right.
$$

where $l$ and $s$ represent the liquid and solid phases, respectively $\alpha, \vec{v}, \rho$ represent the volume fraction, velocity $(\mathrm{m} / \mathrm{s})$, and density $\left(\mathrm{kg} / \mathrm{m}^{3}\right)$ of the liquid and solid phases, respectively, and $t$ is the time (s).

Momentum equation:

$$
\left\{\begin{array}{l}
\frac{\partial\left(\alpha_{s} \rho_{s} \vec{v}_{s}\right)}{\partial t}+\nabla \cdot\left(\rho_{s} \vec{v}_{s} \vec{v}_{s}\right)=-\alpha_{s} \nabla p+\nabla \cdot \tau_{s}+\alpha_{s} \rho_{s} g+\vec{F}_{s l} \\
\frac{\partial\left(\alpha_{l} \rho_{l} \vec{v}_{l}\right)}{\partial t}+\nabla \cdot\left(\rho_{l} \vec{v}_{l} \vec{v}_{l}\right)=-\alpha_{l} \nabla p+\nabla \cdot \tau_{l}+\alpha_{l} \rho_{l} g-\vec{F}_{s l}
\end{array}\right.
$$


where $p$ is the pressure (Pa), $\vec{F}_{s l}$ indicates the momentum exchange source term (N), and $g$ is the gravitational acceleration $\left(\mathrm{m} / \mathrm{s}^{2}\right)$.

(2) Turbulence calculation model

A mixed turbulence model based on shear stress transport (SST) model is used to determine the turbulence characteristics of liquid-solid flow [31-33], and the governing equations can be written as:

$$
\begin{aligned}
\frac{\partial(\rho k)}{\partial t}+u_{j} \frac{\partial(\rho k)}{\partial x_{j}}= & \frac{\partial}{\partial x_{j}}\left[\left(\mu+\sigma_{k} \mu_{t}\right) \frac{\partial k}{\partial x_{j}}\right]+\tau_{i j} \frac{\partial u_{i}}{\partial x_{j}}-\beta^{*} \rho k \omega \\
\frac{\partial(\rho \omega)}{\partial t}+u_{j} \frac{\partial(\rho \omega)}{\partial x_{j}}= & \frac{\partial}{\partial x_{j}}\left[\left(\mu+\sigma_{\omega} \mu_{t}\right) \frac{\partial \omega}{\partial x_{j}}\right]-\beta^{*} \rho \omega^{2}+\frac{\gamma}{\mu_{t}} \tau_{i j} \frac{\partial u_{i}}{\partial x_{j}} \\
& +2\left(1-F_{1}\right) \rho \sigma_{\omega 2} \frac{1}{\omega} \frac{\partial k}{\partial x_{i}} \frac{\partial \omega}{\partial x_{i}} \\
\tau_{i j}= & \mu_{t}\left(2 S_{i j}-\frac{2}{3} \frac{\partial u_{k}}{\partial x_{k}} \delta_{i j}\right)-\frac{2}{3} \rho k \delta_{i j} \\
\left(\sigma_{k} \sigma_{\omega} \beta\right)^{T} & =F_{1}\left(\sigma_{k} \sigma_{\omega} \beta\right)_{1}^{T}+\left(1-F_{1}\right)\left(\sigma_{k} \sigma_{\omega} \beta\right)_{2}^{T}
\end{aligned}
$$

where $k, \omega, S_{i j}, \mu_{t}, \delta_{i j}$, and $\sigma_{k, \omega}$ represent the turbulent kinetic energy, the specific dissipation rate, the rate of deformation, the dynamic viscosity, Kronecker's delta and turbulent Schmidt number, respectively. The blending function $F_{1}$ is designed to be 1 in the near-wall region and zero elsewhere. The coefficient $\gamma=\beta / \beta^{*}-\kappa^{2} /\left(\sigma_{\omega} \sqrt{\beta^{*}}\right)$, and the values of $\kappa, \sigma_{k 1}, \sigma_{k 2}, \sigma_{\omega 1}, \sigma_{\omega 2}$, $\beta_{1}, \beta_{2}$, and $\beta^{*}$ are $0.41,0.85,1.0,0.5,0.856,0.075,0.0827$, and 0.09 , respectively.

\subsection{Grid independence validation}

The commercial software ICEM CFD is used to divide the mesh, the whole channel is divided by the tetrahedral unstructured grid because the structure of the pump is complex, and the blade grid is locally refined (Fig. 2 bII). With the head and hydraulic efficiency of the pump taken as the reference standard, four different grid schemes are selected for numerical calculation under a flow rate of $Q=19.7 \mathrm{~m}^{3} / \mathrm{h}$. The calculation results are shown in Table I. The total number of full runner grids for the four groups of schemes is approximately 3.47 million, 5.40 million, 7.62 million, and 10.86 million, respectively.

Table I: Verification of grid independence.

\begin{tabular}{|c|c|c|c|c|c|}
\hline \multirow{2}{*}{ Grid } & Number of & \multicolumn{2}{|c|}{ Head } & \multicolumn{2}{c|}{ Efficient } \\
\cline { 3 - 6 } & elements & Value $(\mathrm{m})$ & Rate & Value (\%) & Rate \\
\hline Grid-1 & 3466752 & 385.56 & - & 23.54 & - \\
Grid-2 & 5403947 & 375.30 & $2.66 \%$ & 22.03 & $6.41 \%$ \\
Grid-3 & 7617453 & 373.69 & $0.43 \%$ & 21.83 & $0.91 \%$ \\
Grid-4 & 10863830 & 373.04 & $0.17 \%$ & 21.71 & $0.55 \%$ \\
\hline
\end{tabular}

Table I reveals a minimal difference between the head and efficiency values of the four groups of schemes. The variation range of the head and the efficiency value of the numerical calculation results from Grid-2 to Grid-4 gradually decrease. Specifically, the variation range of the head is less than $0.43 \%$, and the range of efficiency variation is less than $0.91 \%$, which meet the calculation accuracy requirements [34]. Considering the computer configuration, calculation workload, economy, and other factors, this study chooses Grid-3 as the grid division scheme of the full-text numerical calculation, that is, the total number of calculation grids of the pump in this study is approximately 7.62 million. 


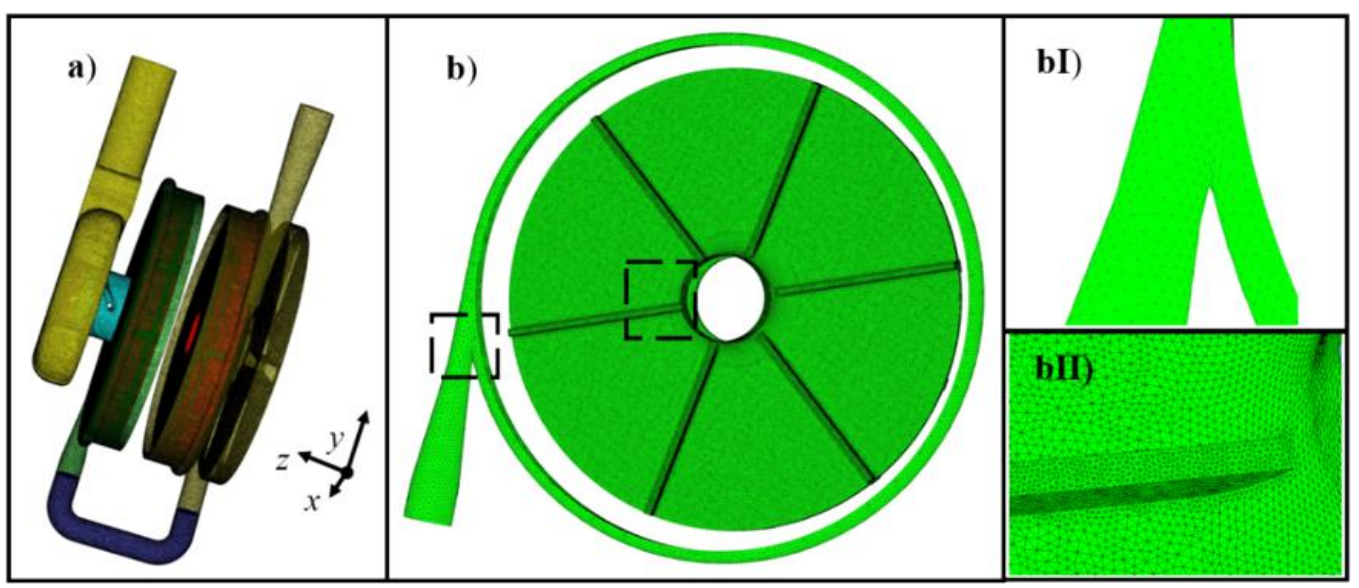

Figure 2: Division of nonstructured grid; a) integral structural grid, b) local structure grid of the firststage impeller and volute, bI) tongue of the first-stage volute, bII) refining the mesh of the blades.

\section{SIMULATION ANALYSIS AND DISCUSSION}

\subsection{Calculation and analysis of energy performance}

Numerical calculation plays an important role in the flow analysis of fluid machinery, especially in the analysis of the internal flow field. The accuracy of the numerical results often depends on whether the turbulence model is appropriate or not. This section is based on ANSYS CFX19.2 software and chooses the SST model [33], and the stable-constant numerical computation of complex flow field in the pump is conducted in this section. The inlet condition is set as the speed inlet to satisfy the needs of different flow rates, and the outlet is set as the pressure outlet. The impeller domain is set as rotating, and the other domains are set as the static coordinate system. The dynamic and static domains are connected by the staging interface. The discretization of the solution is set to a high precision format, the time step is 0.0032 , and the convergence residual is set to $10^{-4}$. At the design speed, the flow rate is selected as $0.3 Q-1.4 Q$ in the experiment. The results of the external characteristics of the numerical calculation and that of the experiment are compared to analyse whether the turbulence model is suitable for the operation of the pump and provide basis for the later numerical calculation.

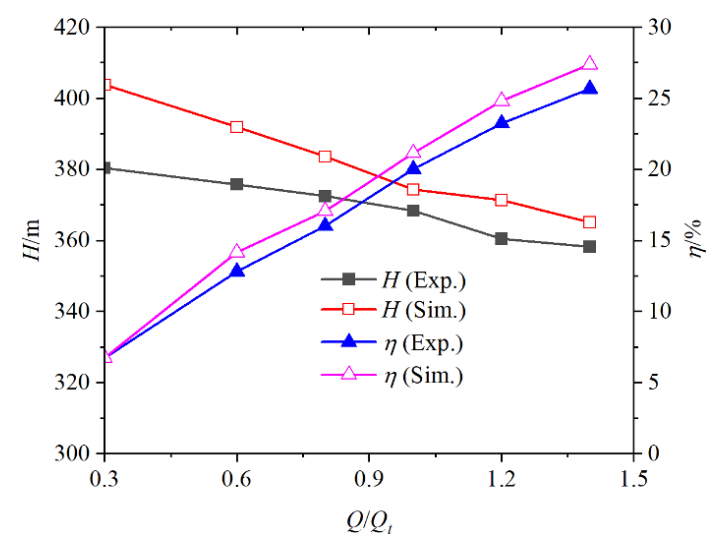

Figure 3: Comparison of test values and simulated values $(C v=0)$.

Fig. 3 shows the similarities and differences between the simulation and experimental results. With the increase in pump flow rate, the pump head decreases gradually, the efficiency increases gradually, and the best efficiency point deflects to the large flow rate. In terms of flow head characteristics, the experimental results have the same trend as the numerical simulation 
results, and the error between the two is less than $5 \%$. When the flow $Q=1.0 Q t, H_{\text {Exp. }}=$ $368.34 \mathrm{~m}$, and $H_{\text {Sim. }}=374.31 \mathrm{~m}$, the head error reaches the minimum value $(1.62 \%)$. From the flow efficiency characteristic curve, the error between the test and simulation results is less than $6 \%$. When the flow $Q=1.0 Q_{t}, \eta_{\text {Exp. }}=20.01 \%$, and $\eta_{\text {Sim. }}=21.14 \%$, the efficiency error is $5.65 \%$. A slight difference exists between the numerical results of the SST turbulence model and the actual results [35], indicating that the SST model can accurately predict the performance of the pump.

\subsection{Effect of particle diameter on performance}

In this study, pure water containing impure particles is used as the flow medium, the solid density is set to $1200 \mathrm{~kg} / \mathrm{m}^{3}$, the viscosity is set to 0 , and the flow inside the pump is a complex solid-liquid two-phase flow. The particle concentration is set as $C_{v}=25 \%$, and the particle diameter is set as $d_{p}=2-6 \mathrm{~mm}$ for the numerical calculation in this section to explore the influence of high solid-phase content on pump performance.

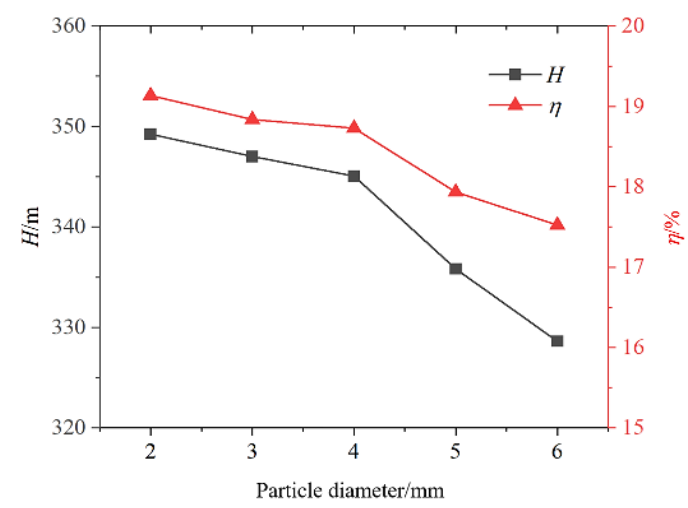

Figure 4: Effect of particle diameter on the pump performance for the rated working condition.

Fig. 4 illustrates that the head and efficiency of the pump decrease with the increase in particle diameter. Given that the particle diameter is less than $4 \mathrm{~mm}$, the particle diameter has minimal effect on the hydraulic head and efficiency. The external characteristics are reduced by $6.32 \%$ and $6.40 \%$ compared with the external characteristic parameters $\left(H_{\text {Exp. }}=368.34 \mathrm{~m}\right.$, $\eta_{\text {Exp. }}=20.01 \%$ ) of the pump under the rated working condition, respectively. When the particle diameter is $6 \mathrm{~mm}$, the pump head and efficiency reach the lowest values, which are $328.61 \mathrm{~m}$ and $17.52 \%$, respectively, decreasing by $10.88 \%$ and $12.44 \%$. The decline in performance parameters is small because the solid particle diameter of this type of pump is less than $4 \mathrm{~mm}$. The cause for the reduction in hydraulic performance is that the larger the particle diameter, the greater the energy required to migrate the particles and the severer the hydraulic loss, leading to a reduction in the pump's external characteristics.

Fig. 5 indicates the velocity of six measuring points at different particle diameters. The circumferential velocity $v_{u}$ is defined as positive in the counterclockwise direction (impeller rotation direction), radial velocity $v_{r}$ is positive in the direction where the hub points to the outer edge of the impeller (centrifugal), and axial velocity $v_{z}$ is positive in the direction of reverse flow (impeller points to the inlet of the pump). As shown in Fig. 5, the velocity components at measuring points 1-6 are mainly based on the circumferential velocity. Strong axial vortex movement is observed in the volute. This movement makes the interaction between solid and liquid phases more intense in the vaneless cavity. The axial velocity at all measuring points is negative due to the pressure difference. The velocity of measuring point 6 is higher than that of the other measuring points by observing the velocity values of all measuring points. The wall near the tongue is subject to great abrasion and impact because measuring point 6 is located near the tongue. 


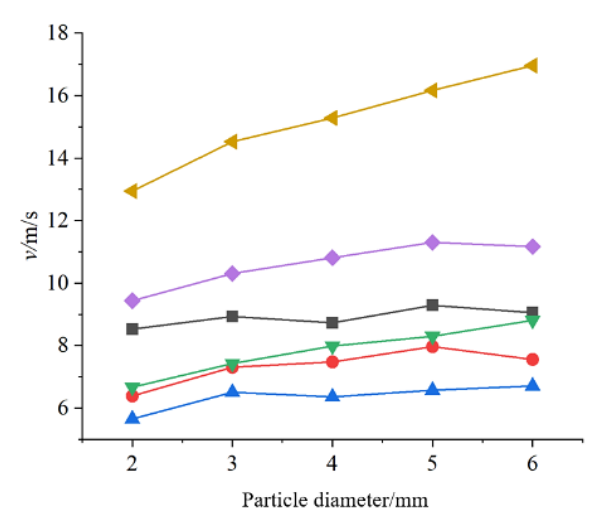

a)

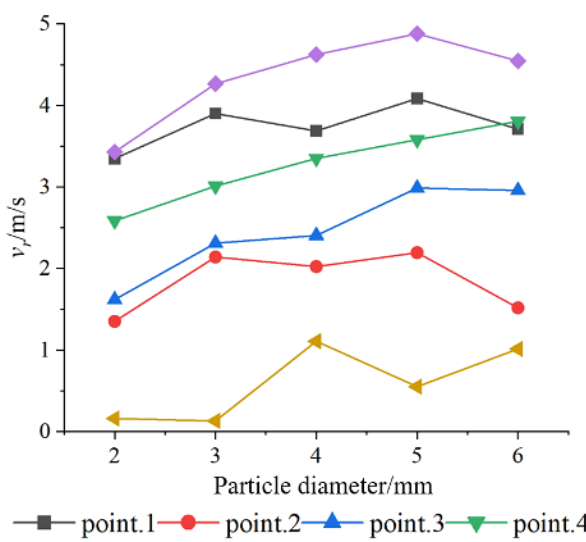

c)

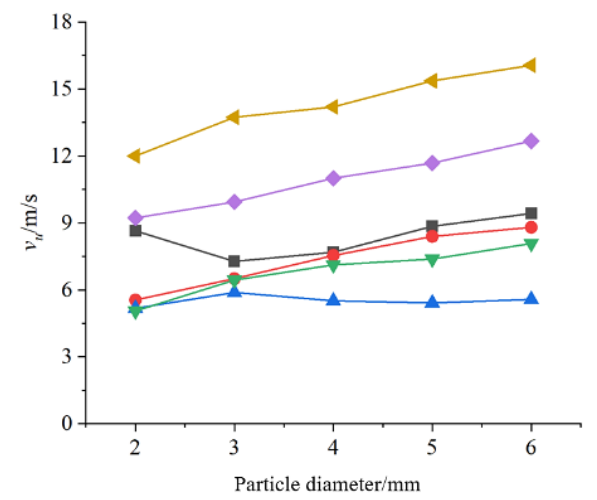

b)

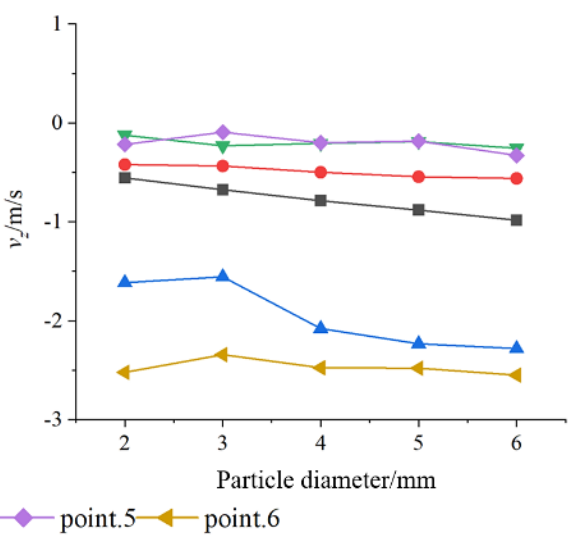

d)

Figure 5: Velocity of measuring points under different particle diameters: a) absolute velocity $(v)$, b) circumferential velocity $\left(v_{u}\right)$, c) radial velocity $\left(v_{r}\right)$, d) axial velocity $\left(v_{z}\right)$.

\subsection{Effect of particle concentration on pump}

In this section, the diameter of solid-phase particles is $4 \mathrm{~mm}$. The influence of the change in solid concentration on the external characteristics and internal flow state of the pump is investigated. The external characteristics of the pump are mainly explained by the change law of head and efficiency. The internal characteristics are illustrated by the distribution cloud of particle velocity and volume fraction under different conditions.

The particle concentration is $5 \%, 10 \%, 15 \%, 20 \%, 25 \%$, and $30 \%$ to explore the influence of particle concentration on the internal flow field of the pump. The variation rule of pump head and efficiency with particle concentration is studied, and the external characteristic curves at different solid volume fractions are obtained, as shown in Fig. 6. The findings indicate the external characteristic performance of the pump at the different solid concentrations at rated operating conditions $\left(Q=19.7 \mathrm{~m}^{3} / \mathrm{h}\right)$. With the increase in the concentration of solid particles, the head and efficiency of the pump decrease. At $5 \%$ particle concentration, the pump head and efficiency decrease by $2.46 \%$ and $0.56 \%$ compared with single-phase condition $\left(C_{v}=0\right)$. When the concentration of particles is $30 \%$, the head of the pump is $327.03 \mathrm{~m}$, which decreases by $9.09 \%$, and the efficiency of the pump is $14.03 \%$, which decreases by $29.97 \%$. Solid-phase volume fraction has a great influence on pump efficiency and head value and shows a regular change with the increase in particle volume fraction and the decrease in pump efficiency and head value. Preliminary analysis shows that the increase in solid phase volume fraction leads to an increase in relative motion between different components and an increase in energy dissipation, leading to a decrease in pump efficiency and head value.

Fig. 7 shows the particle velocity profiles in the leafless cavities at different solid-phase concentrations. Solid velocity is approximately concentric and increases gradually along the 
rotational axis of the volute wall. For $5 \%$ particle concentration, the high-speed area near the impeller outlet is the largest, and the high-speed area opposite the impeller outlet is close to the pressure and suction surfaces of the impeller. The high-speed area is relatively dispersed. With the increase in the concentration of the solid phase, the high-speed area of the solid phase gradually moves closer to the tongue. Given the action of gravity and centrifugal force, more high-speed areas are located at the lower right of $90^{\circ}$ from the impeller outlet. At rated flow rates, increasing particle concentration increases the flow resistance and reduces downflow, causing more particles to flow back near the tongue. At a particle concentration of $5 \%-15 \%$, the high-speed area of the particles is more dispersed, and the wear on the volute wall is reduced. With increase in concentration, the internal high-speed area becomes concentrated, resulting in faster wear of the volute wall near the outer edge of the impeller.

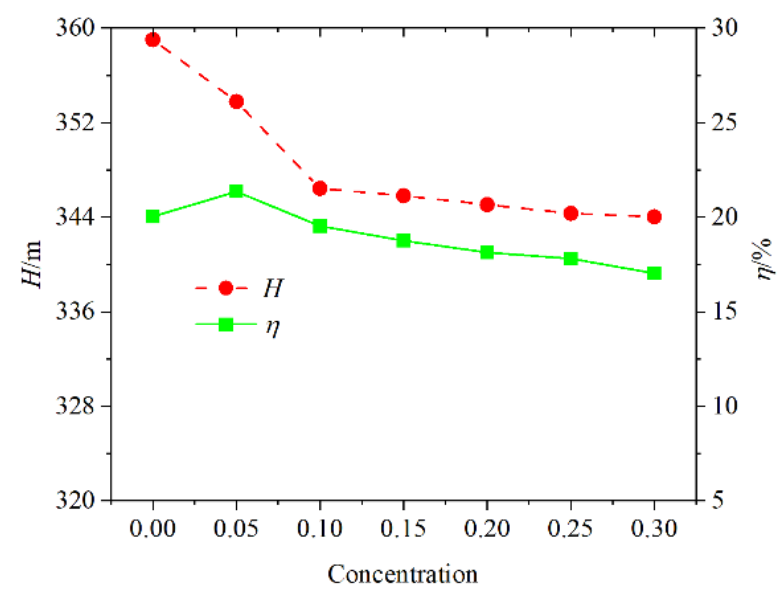

Figure 6: Effect of particle concentration on the pump performance for the rated working condition.

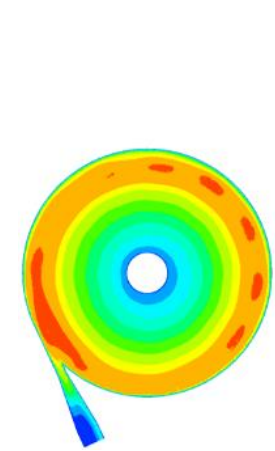

a)

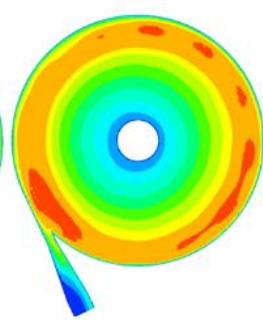

b)

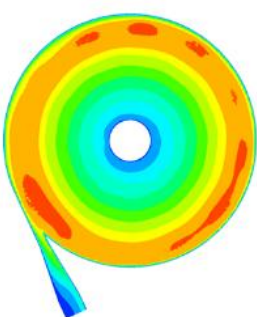

c)

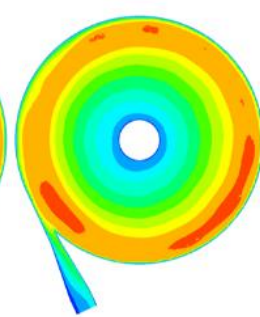

d)

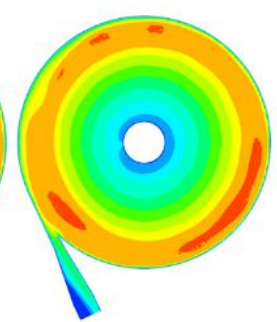

e)

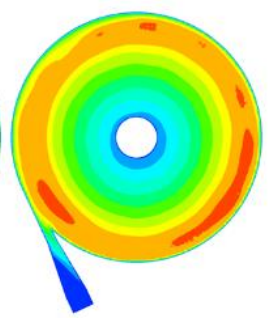

f)

Figure 7: Solid-phase velocity distributions of the volute cavity in section P1 under rated conditions: a) $C_{v}=5 \%$, b) $C_{v}=10 \%$, c) $C_{v}=15 \%$, d) $C_{v}=20 \%$, e) $C_{v}=25 \%$, and f) $C_{v}=30 \%$.

Figs. $8 \mathrm{~b}-\mathrm{d}$ show the volume fraction distribution at different cross sections. An overall observation of Figs. $9 \mathrm{~b}-\mathrm{d}$ show that the area of particle volume fraction is concentrated near the hub, and the volume fraction near the volute outlet is significantly higher than that on the other side. In Fig. 8 b, the area of high solid-phase volume fraction accounts for approximately two thirds of the whole front cover plate, and the solid-phase volume fraction near the impeller outlet is higher than other, and the prerotation strength at the impeller inlet is high, and the pressure is low. Thus, numerous particles remain in the vaneless chamber. In Figs. $8 \mathrm{c}$ and $8 \mathrm{~d}$, the particle volume fraction and the area of distribution in the flow channel of the impeller are small. The closer the impeller rear cover plate, the smaller the solid-phase distribution area in the flow channel. This condition indicates that under the action of centrifugal force, most particles leave the impeller flow path before reaching the working surface. This phenomenon 
reduces the wear of particles on the impeller and the impact loss on the impeller outflow, thereby increasing the service life of the impeller. In Fig. 9 a, the pressure value at the monitoring point decreases slowly with the increase in concentration, resulting in a decrease in pump head and efficiency.

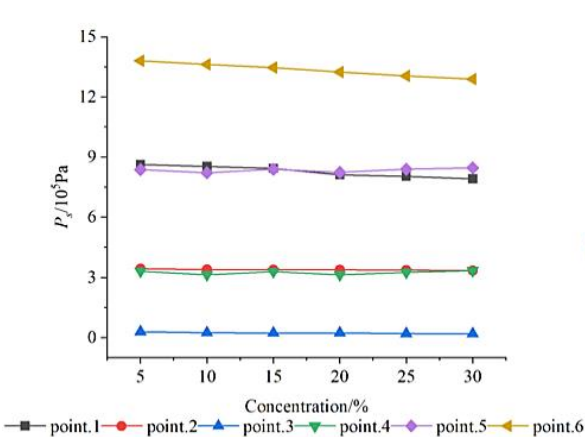

a)

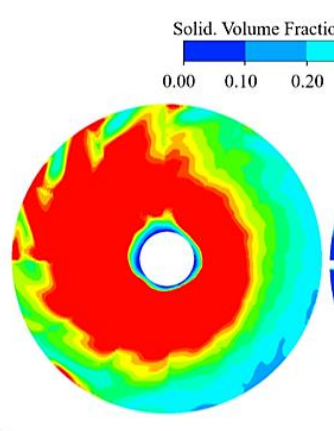

b)

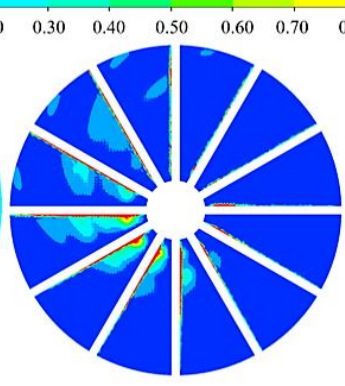

c)

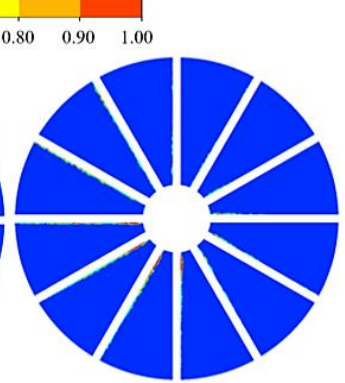

d)

Figure 8: Static pressure at monitoring points and volume fraction distributions of solid phase at different profiles: a) at the profile of $\mathrm{P} 1, \mathrm{~b})$ at the profile of $\mathrm{P} 2\left(C_{v}=25 \%\right)$, c) at the profile of $\mathrm{P} 3$ $\left.\left(C_{v}=25 \%\right), \mathrm{d}\right)$ at the profile of $\mathrm{P} 4\left(C_{v}=25 \%\right)$.

\section{CONCLUSION AND FUTURE WORK}

In this study, under the condition of solid-liquid two-phase flow, the influence of high solidphase fraction medium on the external characteristics and internal flow field of a new two-stage vortex pump is analysed by using hydrodynamics software ANSYS CFD19.2 and the SST model. The main conclusions are as follows:

(1) Under the single-phase condition, the SST model can predict the external characteristics of the pump. With the increase in flow rate, the best efficiency point of the pump shifts to the direction of a high flow rate.

(2) The external characteristics of the pump decrease linearly with the increase in particle size. When the particle size is less than $4 \mathrm{~mm}$, the head and efficiency of the pump decrease slightly by up to $6.32 \%$ and $6.40 \%$, respectively. The velocity and pressure in the impeller passage show a circular distribution and gradually increase from the hub to the outer edge of the impeller. Large velocity and pressure differences are observed near the separator tongue, causing the wear and impact of the pump body.

(3) With the increase in particle concentration, the flow resistance and viscosity increase, and a severe prerotation occurs at the inlet of the first-stage impeller. This prerotation is characterized by the increase in the volume fraction of particles in the vaneless cavity, leading to the increase in wear of the pump. The contact probability between components increases, and the energy needed to maintain the movement of particles increases, resulting in a decrease in the pressure in the pump and a decrease in the head and efficiency of the pump. Under the action of circulating flow and through flow, most particles leave the vaneless cavity before entering the impeller channel. Thus, the wear on the impeller blades is relatively small.

In this study, high-particle-diameter and high-concentration particles are selected to study their effects on the external characteristics and internal flow field of multistage vortex pumps. The results show that with the increase in particle diameter and concentration, the external characteristics of the pump decrease to some extent, and the particles have minimal abrasion on the impeller. This research ignores the temperature change, and the particles are a single homogeneous spherical structure. The influence of particle shape, particle density, and viscosity on the results is disregarded. The next step is to increase these factors for enhancing the credibility of the results. 


\section{REFERENCES}

[1] Wei, R.; Zimmermann, W. (2017). Microbial enzymes for the recycling of recalcitrant petroleumbased plastics: how far are we?, Microbial Biotechnology, Vol. 10, No. 6, 1308-1322, doi:10.1111/1751-7915.12710

[2] Hosseini, S. E.; Akhavan, A. N.; Bahrami, M. (2020). Designing an integrated model of oil and gas management with a SWOT approach: the case of NIOC, Technical Journal, Vol. 14, No. 4, 440-445, doi: $10.31803 / \mathrm{tg}-20200514234542$

[3] Okolie, J. A.; Nanda, S.; Dalai, A. K.; Berruti, F.; Kozinski, J. A. (2020). A review on subcritical and supercritical water gasification of biogenic, polymeric and petroleum wastes to hydrogen-rich synthesis gas, Renewable and Sustainable Energy Reviews, Vol. 119, Paper 109546, 15 pages, doi:10.1016/j.rser.2019.109546

[4] Rios, M. L. V.; González, A. M.; Lora, E. E. S.; del Olmo, O. A. A. (2018). Reduction of tar generated during biomass gasification: a review, Biomass and Bioenergy, Vol. 108, 345-370, doi:10.1016/j.biombioe.2017.12.002

[5] Karl, J.; Pröll, T. (2018). Steam gasification of biomass in dual fluidized bed gasifiers: a review, Renewable and Sustainable Energy Reviews, Vol. 98, 64-78, doi:10.1016/j.rser.2018.09.010

[6] Tan, M.; Lian, Y.; Liu, H.; Wu, X.; Ding, R. (2018). Visualizing test on the pass-through and collision characteristics of coarse particles in a double blade pump, International Journal of Naval Architecture and Ocean Engineering, Vol. 10, No. 1, 1-8, doi:10.1016/j.ijnaoe.2017.06.003

[7] Wang, R. K.; Guan, Y. J.; Jin, X.; Tang, Z. J.; Zhu, Z. C.; Su, X. H. (2021). Impact of particle sizes on flow characteristics of slurry pump for deep-sea mining, Shock and Vibration, Vol. 2021, Paper 6684944, 13 pages, doi:10.1155/2021/6684944

[8] Yoshinaga, T.; Sato, Y. (1996). Performance of an air-lift pump for conveying coarse particles, International Journal of Multiphase Flow, Vol. 22, No. 2, 223-238, doi:10.1016/03019322(95)00067-4

[9] Mrinal, K. R.; Samad, A. (2018). Performance prediction of kinetic and screw pumps delivering slurry, Proceedings of the Institution of Mechanical Engineers, Part A: Journal of Power and Energy, Vol. 232, No. 7, 898-911, doi:10.1177/0957650918760161

[10] Shi, B.; Wei, J.; Zhang, Y. (2017). A novel experimental facility for measuring internal flow of solid-liquid two-phase flow in a centrifugal pump by PIV, International Journal of Multiphase Flow, Vol. 89, 266-276, doi:10.1016/j.ijmultiphaseflow.2016.11.002

[11] Fernandez-Jimenez, A.; Blanco-Marigota, E.; Yosry, A. G.; Fernandez-Pacheco, V.-M.; AlvarezAlvarez, E. (2020). Evaluation of a vertical axis hydrokinetic turbine for water channels, DYNA, Vol. 96, No. 2, 194-199, doi:10.6036/9883

[12] Wang, H. L.; Long, B.; Yang, Y.; Xiao, Y.; Wang, C. (2020). Modelling the influence of inlet angle change on the performance of submersible well pumps, International Journal of Simulation Modelling, Vol. 19, No. 1, 100-111, doi:10.2507/IJSIMM19-1-506

[13] Ben-Ami, Y.; Uzi, A.; Levy, A. (2016). Modelling the particles impingement angle to produce maximum erosion, Powder Technology, Vol. 301, 1032-1043, doi:10.1016/j.powtec.2016.07.041

[14] Ben-Ami, Y.; Levy, A. (2016). Absorbed shear energy during solid particle impact on ductile surface, Wear, Vols. 368-369, 162-172, doi:10.1016/j.wear.2016.09.021

[15] Lin, N.; Arabnejad, H.; Shirazi, S. A.; McLaury, B. S.; Lan, H. (2018). Experimental study of particle size, shape and particle flow rate on Erosion of stainless steel, Powder Technology, Vol. 336, 70-79, doi:10.1016/j.powtec.2018.05.039

[16] Kamyar, A.; Aminossadati, S. M.; Leonardi, C. R.; Sasmito, A. P.; Poncet, S. (2020). Flow characterisation of monopropylene glycol ice slurry through a horizontal U-bend: a numerical approach, European Journal of Mechanics - B/Fluids, Vol. 82, 93-105, doi: 10.1016/ j.euromechflu.2020.03.004

[17] Kamyar, A.; Aminossadati, S. M.; Leonardi, C. R. (2018). Thermo-hydrodynamics of a helical coil heat exchanger operated with a phase-change ice slurry as a refrigerant, Heat Transfer Engineering, Vol. 40, No. 3-4, 283-294, doi:10.1080/01457632.2018.1428989

[18] Safaei, M. R.; Ahmadi, G.; Goodarzi, M.; Kamyar, A.; Kazi, S. N. (2016). Boundary layer flow and heat transfer of FMWCNT/water nanofluids over a flat plate, Fluids, Vol. 1, No. 4, Paper 31, 13 pages, doi: $10.3390 /$ fluids 1040031 
[19] Kannojiya, V.; Kumar, S.; Kanwar, M.; Mohapatra, S. K. (2016). Simulation of erosion wear in slurry pipe line using CFD, Applied Mechanics and Materials, Vol. 852, 459-465, doi:10.4028/www.scientific.net/AMM.852.459

[20] Kannojiya, V.; Deshwal, M.; Deshwal, D. (2018). Numerical analysis of solid particle erosion in pipe elbow, Materials Today: Proceedings, Vol. 5, No. 2, 5021-5030, doi:10.1016/ j.matpr.2017.12.080

[21] Kannojiya, V.; Das, A. K.; Das, P. K. (2020). Proposal of hemodynamically improved design of an axial flow blood pump for LVAD, Medical \& Biological Engineering \& Computing, Vol. 58, No. 2, 401-418, doi:10.1007/s11517-019-02097-5

[22] Kannojiya, V.; Kumar, S. (2020). Assessment of optimum slurry pipe design for minimum erosion, Scientia Iranica, Vol. 27, No. 5, 2409-2418, doi:10.24200/sci.2019.52073.2519

[23] Zhang, M.; Kang, Y.; Wei, W.; Li, D.; Xiong, T. (2021). CFD investigation of the flow characteristics of liquid-solid slurry in a large-diameter horizontal pipe, Particulate Science and Technology, Vol. 39, No. 6, 712-725, doi:10.1080/02726351.2020.1799274

[24] Zhang, M. D.; Li, D.; Kang, Y.; Huang, M.; Yuan, M. (2021). Experimental study on the rock erosion performance of a pulsed abrasive supercritical $\mathrm{CO}_{2}$ jet, Journal of Petroleum Science and Engineering, Vol. 201, Paper 108489, 12 pages, doi:10.1016/j.petrol.2021.108489

[25] Fang, Z. L.; Gao, X.; Tao, X.; Li, D.; Zhang, M. D.; Xiong, T.; Jiang, P. (2019). Impact performance of Helmholtz self-excited oscillation waterjets used for underground mining, Applied Sciences, Vol. 9, No. 16, Paper 3235, 18 pages, doi:10.3390/app9163235

[26] Kadambi, J. R.; Charoenngam, P.; Subramanian, A.; Wernet, M. P.; Sankovic, J. M.; Addie, G.; Courtwright, R. (2004). Investigations of particle velocities in a slurry pump using PIV: Part 1, The tongue and adjacent channel flow, Journal of Energy Resources Technology, Vol. 126, No. 4, 271-277, doi: $10.1115 / 1.1786928$

[27] Yang, M. G.; Gao, B.; Liu, D.; Gu, H. F.; Li, H. (2008). Experimental investigation of salt-out twophase flow in a vortex pump by PDPA measurements, Journal of Engineering Thermophysics, Vol. 29, No. 2, 237-240, doi:10.3321/j.issn:0253-231X.2008.02.015

[28] Zhang, D. W.; Yang, M. G.; Gao, B.; Lu, B. Y. (2013). Particle concentration distribution and its effect on performance in a vortex pump, Fluid Machinery, Vol. 41, No. 5, 15-18, doi:10.3969/j.issn.1005-0329.2013.05.004

[29] Qian, J.; Yang, M.; Cao, Y. S.; Gao, B.; Wang, H. Y. (2014). CFD-PBM coupled calculation on liquid-solid two-phase flow field in a vortex pump, Fluid Machinery, Vol. 42, No. 4, 23-27, doi:10.3969/j.issn.1005-0329.2014.04.005

[30] Islam, M. T.; Nguyen, A. V. (2021). Effect of particle size and shape on liquid-solid fluidization in a HydroFloat cell, Powder Technology, Vol. 379, 560-575, doi:10.1016/j.powtec.2020.10.080

[31] Rahman, M. M.; Vuorinen, V.; Taghinia, J.; Larmi, M. (2019). Wall-distance-free formulation for SST $k$ - $\omega$ model, European Journal of Mechanics - B/Fluids, Vol. 75, 71-82, doi:10.1016/ j.euromechflu.2018.11.010

[32] Lu, L.; Wang, C.; Qin, D. (2020). Numerical investigations of flow characteristics of a pumpjet propulsor in oblique inflow, Applied Ocean Research, Vol. 103, Paper 102343, 12 pages, doi: 10.1016/j.apor.2020.102343

[33] Wang, F. (2016). Research progress of computational model for rotating turbulent flow in fluid machinery, Transactions of the Chinese Society for Agricultural Machinery, Vol. 47, No. 2, 1-14, doi:10.6041/j.issn.1000-1298.2016.02.001

[34] Wu, X. F.; Feng, J. S.; Liu, H. L.; Ding, J.; Chen, H. L. (2017). Performance prediction of singlechannel centrifugal pump with steady and unsteady calculation and working condition adaptability for turbulence model, Transactions of the Chinese Society of Agricultural Engineering, Vol. 33, No. 1, 85-91, doi:10.11975/j.issn.1002-6819.2017.z1.013

[35] Guo, G.; Zhang, R.; Yu, H. (2020). Evaluation of different turbulence models on simulation of gasliquid transient flow in a liquid-ring vacuum pump, Vacuum, Vol. 180, Paper 109586, 8 pages, doi:10.1016/j.vacuum.2020.109586 